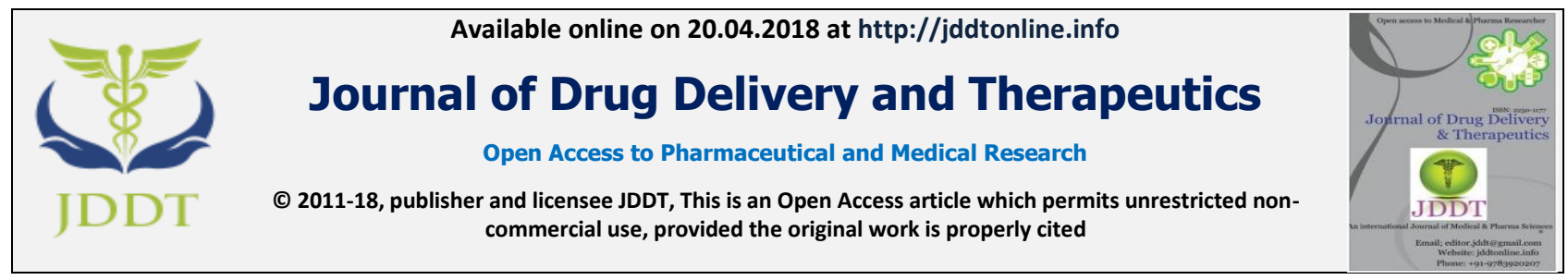

Open $\odot$ Access

Research Article

\title{
EVALUATION OF A MODIFIED BIOMATERIAL OF TYMPANOTONUS FUSCATA SHELL POWDER I: FORMULATION OF THEOPHYLLINE HYDRATE AND HYDROCHLOROTHIAZIDE TABLETS
}

\author{
Kenneth C. Ugoeze ${ }^{1 *}$, Amarauche Chukwu ${ }^{2}$ \\ ${ }^{\mathbf{1}}$ Department of Pharmaceutics \& Pharmaceutical Technology, Faculty of Pharmaceutical Sciences, University of Port Harcourt, Nigeria \\ ${ }^{2}$ Department of Pharmaceutical Technology and Industrial Pharmacy, Faculty of Pharmaceutical Sciences, University of Nigeria, Nsukka, \\ Nigeria
}

\section{ABSTRACT}

A modified biomaterial of periwinkle shell powder, MBPSP derivative of Tympanotonus fuscata shell was applied as a diluent in theophylline hydrate (TPH) and hydrochlorothiazide (HCTZ) tablets. A $100 \mathrm{~g}$ of the pulverized periwinkle shell was digested with $166.0 \mathrm{ml}$ of $2 \mathrm{M}$ hydrochloric acid, filtered and neutralized with $5 \mathrm{M}$ sodium hydroxide. Ortho-phosphoric acid was added drop wise until a thick, dehydrated mass was obtained. It was dried at $60^{\circ} \mathrm{C}$ and milled to $250 \mu \mathrm{m}$ size and designated as MBPSP. Using this, batches of granules containing TPH $(100 \mathrm{mg})$ and HCTZ $(50 \mathrm{mg})$ were produced by the wet granulation technique alongside lactose and dicalcium phosphate dihydrate (DCP). They were tableted at $7.55 \mathrm{kN}$ using a $10.50 \mathrm{~mm}$ diameter die and flat-faced punch on a hydraulic hand press. Tablet properties were evaluated. The weight variation for the TPH or HCTZ tablets produced from MBPSP, lactose or DCP were between $0.03-0.32 \%$. The total drug content for the respective batches of tablets was within 85-118 \% of the claimed label potency. Though the respective batches of tablets of TPH and HCTZ containing MBPSP, lactose or DCP maintained significantly high values of mechanical strength, the tablets of TPH and HCTZ prepared with DCP generally showed significantly higher values of mechanical strength than those of MBPSP and lactose. Dissolution profile showed that at $45.00 \mathrm{~min}, 73.13,87.72$ and $87.45 \%$ of TPH was released from the tablets containing lactose, MBPSP and DCP respectively while at $60.00 \mathrm{~min}, 64.58$, 57.84 and $66.00 \%$ of HCTZ was dissolved from the tablets having lactose, MBPSP and DCP respectively. Though MBPSP compared significantly favourably with lactose and DCP in the various tablet parameters evaluated, the tablets of TPH or HCTZ comprising MBPSP displayed very significant shorter tablet disintegration time and also maintained a significantly greater mechanical strength in comparison to lactose and DCP. Therefore, MBPSP could be a very useful excipient in the formulation of TPH and HCTZ immediate-release tablets.

Keywords: Modified biomaterial, Tympanotonus fuscata, periwinkle, shell, theophylline hydrate, hydrochlorothiazide, tablet.

Article Info: Received 22 Jan, 2018; Review Completed 16 April 2018; Accepted 17 April 2018; Available online 20 April 2018

\section{Cite this article as:}

Ugoeze KC, Chukwu A, Evaluation of a modified biomaterial of Tympanotonus fuscata shell powder I: formulation of theophylline hydrate and hydrochlorothiazide tablets, Journal of Drug Delivery and Therapeutics. 2018; 8(2):176-180 DOI: http://dx.doi.org/10.22270/jddt.v8i2.1698

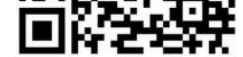

*Address for Correspondence:

Kenneth C. Ugoeze, Department of Pharmaceutics \& Pharmaceutical Technology, Faculty of Pharmaceutical Sciences, University of Port Harcourt, Nigeria

\section{INTRODUCTION}

Tablets are compact dosage systems that comprise active pharmaceutical ingredient (API) and other inert substances described as excipients. It may or may not contain bulking agents. Tablets may be produced either by moulding or compression procedure. Tablets are widely used owing to their continuous advantages and appreciations by patients ${ }^{1}$. When a tablet is administered, it is anticipated to be moved to the spot where its active content will accomplish its therapeutic activities in its active form in the concentration that will be adequate and at the accurate rate to realize the therapeutic expectations. The tablet should be stable in its physical and chemical state in order to establish its potency, safety over its shelf life. The manufacture of a tablet is projected to be cost-effective and it should be appreciable for use by the patient ${ }^{2}$. The composition of a tablet encompasses numerous ingredients besides the API. There are several sorts of excipients including the bulking agent, binder, lubricant, disintegrant, anti- 
adherent, a colouring agent, flavouring agent, etc ${ }^{2}$. The utilization of excipients takes a vital position in the composition of tablets and other pharmaceutical dosage systems as they help in the production, safety, stability and therapeutic activity of any dosage form ${ }^{\mathbf{3 , 4}}$. Excipients are also required in the formulation of a good tablet at the vital tablet press speed, assist in the flow, compressibility of powders as well as the capability of the tablet to be removed from the tablet press without crumbling. Other use of the inert materials is that they aid in the mechanical strength, break-down, ecstasy, etc., and the overall functionality of the tablet ${ }^{5}$. Tablets may be prepared by blending dry pulverized substances and compacting them into tablets in a method known as the direct compression (DC). The powdered ingredients employed in the DC ought to remain mixed with other ingredients without segregation. In addition, such powder mixtures are anticipated to maintain effective flowability, compressibility and be removable from the tablet press without tablet defects. They are anticipated to possess enough mechanical strength and discharge the API in the expected time frame. Excipients that do not possess these qualities will be employed in tablet formulation by the wet granulation (WG) method. Excipients that are suitable for the WG method when blended will need to be kept stable without segregating by the use of an adhesive ingredient described as a binder or granulating agent. Some micronized ingredients require a degree of homogenizing before the addition of a granulating agent while some may not. However, wet massing attained by employing a binder may be likened to the manipulation of dough as in the manufacture of bread. The subsequent wet mixture obtained is pushed through a suitable sieve size and dried at a regulated temperature. The dried form is rescreened over another lower aperture of sieves to yield granules.

Tympanotonus fuscata var Radula (L) traditionally known as the periwinkle is protected with shell and fits in as a Mollusca, the major aquatic animal with exoskeleton defined as a shell. The blood of molluscs is rich in a liquid form of calcium which concentrates out and can crystallize as calcium carbonate. The layers of $\mathrm{CaCO}_{3}$ may integrate conchiolin which merges the $\mathrm{CaCO}_{3}$ crystals together. Large aggregates of shells might constitute sediment and become compacted into limestone ${ }^{6}$.

In this work, the pulverized shell of Tympanotonus fuscata was modified and employed as a bulking agent in the formulation of theophylline hydrate and hydrochlorothiazide tablets by the wet granulation method using lactose and dicalcium phosphate dihydrate (DCP) as standards. The processing and introductory assessment of the characteristics of the biomaterial of $T$. fuscata shell as pharmaceutical excipient has been documented ${ }^{6}$. The physico-chemical characteristics of the modified biomaterial of Tympanotonus fuscata shell powder (MBPSP) considered as pharmaceutical excipient has also been acknowledged in the literature ${ }^{7}$. Ugoeze and Udeala reported the application of a bio-ash derived from the periwinkle shell as a carbon dioxide $\left(\mathrm{CO}_{2}\right)$ donor in the design of an effervescent low dose aspirin tablet ${ }^{8}$.

\section{MATERIALS AND METHODS}

\section{Materials}

The following were used as procured and includes: Lactose (Surechem, England), hydrochloric acid ( $\mathrm{HCl}$ ), sodium hydroxide $(\mathrm{NaOH})(\mathrm{M} \& \mathrm{~B}$, England), gelatin (Fisher, USA), lactose, dicalcium phosphate dihydrate (DCP) (Rousselot, Belgium), theophylline hydrate (TPH), corn starch, magnesium stearate, talc, ethanol (BDH, England) and hydrochlorothiazide (HCTZ) (donated by Juhel Nigeria Ltd).

\section{Methods}

\section{Preparation of modified biomaterial of Tympanotonus fuscata shell powder}

The method reported by Ugoeze and Chukwu in the production of the modified biomaterial of Tympanotonus fuscata shell powder was adopted (7). A $100 \mathrm{~g}$ quantity of the milled shell of Tympanotonus fuscata was digested with $166.0 \mathrm{ml}$ of $2 \mathrm{M} \mathrm{HCl}$ and filtered. The clear acidic solution was neutralized with 5 $\mathrm{M} \mathrm{NaOH}$ to produce an abundant white precipitate which was washed severally. Ortho-phosphoric acid was added drop wise to the thick aqueous suspension of the precipitate until a thick, dehydrated mass was obtained. The mass was dried at $60^{\circ} \mathrm{C}$ in hot air oven (Uniscope, England). It was classified with a $250 \mu \mathrm{m}$ stainless steel sieve (Retch, Germany) and stored in amber coloured powder container. This powder is referred to in this work as the modified biomaterial of periwinkle shell powder (MBPSP).

\section{Formulation of tablet}

Table 1: Formula for producing theophylline hydrate (TPH) tablets using MBPSP or lactose or DCP as diluents in wet granulation. Each tablet contains $100 \mathrm{mg}$ of theophylline hydrate and weighs $300 \mathrm{mg}$.

\begin{tabular}{|l|c|}
\hline Ingredient & Amount $(\% \mathrm{w} / \mathrm{w})$ \\
\hline Theophylline hydrate $(\mathrm{TPH})$ & 33.33 \\
\hline Gelatin & 2.00 \\
\hline Maize starch & 10.00 \\
\hline Magnesium stearate & 0.50 \\
\hline Talc & 0.50 \\
\hline Lactose or MBPSP or DCP & 53.17 \\
\hline
\end{tabular}

Table 2: Formula for producing hydrochlorothiazide (HCTZ) tablets using MBPSP or lactose or DCP as diluents. Each tablet contains $50 \mathrm{mg}$ of HCTZ and weighs $300 \mathrm{mg}$.

\begin{tabular}{|l|c|}
\hline Ingredient & Amount $(\% \mathrm{w} / \mathrm{w})$ \\
\hline Hydrochlorothiazide (HCTZ) & 16.66 \\
\hline Gelatin & 2.00 \\
\hline Corn starch & 10.00 \\
\hline Magnesium stearate & 0.50 \\
\hline Talc & 0.50 \\
\hline Lactose or MBPSP or DCP & 69.84 \\
\hline
\end{tabular}

\section{Granulation}

Granules containing TPH or HCTZ were produced by the method of wet granulation using the respective formulations shown in Tables 1 and 2. In each case, the 
respective drugs were mixed with corn starch and the other diluents were added in bits and each time triturated to homogeneity. Gelatin dissolved in a little amount of hot water was added to the powder mix and triturated to yield a fairly wet mix which sprinkled with water in bits and kneaded. It was screened through sieve $10(1.7 \mathrm{~mm})$ and left in a hot air oven (Uniscope, England) at $60{ }^{\circ} \mathrm{C}$ to dry to a constant weight. The batches of the dried masses were rescreened with sieve $16(1.00 \mathrm{~mm})$ and the granules obtained were stored in airtight amber coloured glass containers.

\section{Compression of tablets}

The respective batches of granules prepared with TPH or HCTZ and containing MBPSP, lactose or DCP were lubricated with magnesium stearate and talc respectively and compressed for $30 \mathrm{~s}$ at a predetermined load of 7.35 $\mathrm{kN}$ employing a $10.5 \mathrm{~mm}$ diameter die and flat-faced punches on a hydraulic hand press (Model C, Carver Laboratory Press, Menomonee Falls, WI. USA). All the compressed tablets were left for $24 \mathrm{~h}$ before they were analyzed to allow for possible recovery from stress.

\section{Evaluation of tablets}

\section{Uniformity of tablet weight}

Twenty tablets were selected randomly from each batch of tablets of TPH or HCTZ prepared with either MBPSP, lactose or DCP were weighed one after the other on an electronic analytical balance (Mettler, Germany) ${ }^{9}$.

\section{Uniformity of tablet thickness}

The thickness of the respective batches of tablets tested for uniformity of weight was measured with a micrometre screw gauge (VIS, Poland).

\section{Tablet hardness}

Ten tablets each from the batches of TPH or HCTZ prepared with either MBPSP, lactose of DCP were selected from each batch and their hardness (9) were evaluated using a digital hardness tester (DBK Instruments, England). The mean hardness value was calculated.

\section{Tablet friability}

Ten tablets, each from TPH or HCTZ prepared either with MBPSP, lactose or DCP respectively were dusted and weighed. In turn, each was introduced in a tablet friabilator (Veego Tablet Friability Test Apparatus, India) set at 25 revolution per minute (rpm) for $4 \mathrm{~min}$ after which the tablets were respectively brought out, freed of dust and reweighed. Friability was calculated for the respective batches as per cent loss in weight of the entire tablets.

\section{Tablet disintegration time}

The disintegration time of six tablets from each batch containing TPH or HCTZ and containing either MBPSP, lactose or DCP was evaluated using disintegration apparatus (Veego Disintegration Apparatus, India). The instrument consists of a rigid basket-rack assembly holding six cylindrical glass tubes. A $1 \mathrm{~L}$ volume of $0.1 \mathrm{~N} \mathrm{HCl}$ in a glass beaker was used as disintegrating medium, maintained at $37 \pm 1^{\circ} \mathrm{C}$. Disintegration was seen as complete when no residue of unbroken tablet remained on the screen of the test apparatus ${ }^{9}$.

\section{Tablet total drug content}

Ten intact tablets of TPH or HCTZ prepared either with MBPSP, lactose or DCP were taken from each batch and crushed. The weight of powders equivalent to the mean weight of the respective batches was analyzed spectrophotometrically for its total drug content.

\section{Tablet tensile strength}

This was calculated from the equation: $T=2 P / \pi d t$

\section{Dissolution rate test for tablets}

The dissolution rate for TPH or HCTZ tablets containing either MBPSP, lactose or DCP respectively were carried out using dissolution apparatus (Erweka DT 80, Germany) (apparatus 2, the paddle method and apparatus 1, the basket method, operated at the speed of 50 and 100 revolutions per minute (rpm) for TPH and HCTZ tablets respectively each in $900 \mathrm{ml}$ of $0.1 \mathrm{~N} \mathrm{HCl}$ maintained at $37 \pm 1^{\circ} \mathrm{C}(9)$. For each procedure, a $5.0 \mathrm{ml}$ of sample was withdrawn from the respective dissolution medium at time intervals between 5.0- 60.0 min, replacing same with $5 \mathrm{ml}$ of plain $0.1 \mathrm{~N} \mathrm{HCl}$ solution each time. The absorption of the samples was read in a Spectrophotometer 160-A (Japan) at the respective maximum wavelengths of 268 and $271 \mathrm{~nm}$ for TPH and HCTZ respectively.

\section{Statistical analysis}

All statistical analysis of data involving ANOVA was carried out using the IBM SPSS Statistics 20 software.

\section{RESULTS AND DISCUSSIONS}

\section{Physical properties of tablets}

The characteristics of the TPH or HCTZ prepared with MBPSPS, lactose or DCP are shown in Tables 3 and 4 respectively.

\section{Appearance of tablets}

The tablets of TPH and HCTZ produced with lactose, MBPSP or DCP were glossy without discolouration.

\section{Tablet weight uniformity and thickness}

The weight variation for the TPH or HCTZ tablets prepared with MBPSP, lactose or DCP were between $0.03-0.32 \%$. The British Pharmacopoeia ${ }^{9}$ specified up to $7.5 \%$ for weight variation for tablets weighing 130$324 \mathrm{mg}$. The low values of weight variation may be due to consistencies in the flow of granules at compression press. There were no significant differences in the weights of tablets in the respective batches of TPH and HCTZ between MBPSP and lactose ( $p>0.05)$, though, there was a slight difference in weight between MBPSP, lactose and DCP $(p=0.04)$. A similar observation was also recorded at the respective tablet thickness for TPH and HCTZ for all the diluents under study. 
Table 3: Properties of theophylline hydrate tablet prepared with MBPSP, lactose or DCP.

\begin{tabular}{|l|c|c|c|}
\hline Tablet parameter & MBPSP & Lactose & DCP \\
\hline Uniformity of weight $(\mathrm{mg})$ & $299.55 \pm 0.55$ & $299.03 \pm 0.11$ & $300.10 \pm 0.80$ \\
\hline Thickness (mm) & $2.05 \pm 0.01$ & $2.42 \pm 0.02$ & $2.03 . \pm 0.01$ \\
\hline Drug Content (\%) & $90.10 \pm 0.01$ & $89.72 \pm 0.04$ & $96.76 \pm 0.05$ \\
\hline Disintegration time (min) & $2.10 \pm 0.10$ & $4.13 \pm 0.15$ & $12.92 \pm 0.06$ \\
\hline Hardness (N) & $143.39 \pm 0.37$ & $100.43 \pm 0.08$ & $215.00 \pm 0.02$ \\
\hline Friability (\%) & $0.60 \pm 0.02$ & $0.51 \pm 0.02$ & $0.90 \pm 0.02$ \\
\hline Tensile strength $\left(\mathrm{mN} / \mathrm{m}^{2}\right)$ & $3349 \pm 0.61$ & $2496.39 \pm 0.59$ & $6389.39 \pm 0.56$ \\
\hline HFR $^{*}$ & $217.57 \pm 0.11$ & $193.36 \pm 0.08$ & $236.36 \pm 0.05$ \\
\hline
\end{tabular}

Table 4: Properties of hydrochlorothiazide tablets produced with MBPSP, lactose or DCP.

\begin{tabular}{|l|c|c|c|}
\hline Tablet parameter & MBPSP & Lactose & DCP \\
\hline Uniformity of weight $(\mathrm{mg})$ & $299.54 \pm 0.56$ & $299.10 \pm 0.11$ & $300.10 \pm 0.80$ \\
\hline Thickness (mm) & $2.43 \pm 0.01$ & $2.39 \pm 0.06$ & $2.47 \pm 0.02$ \\
\hline Drug Content (\%) & $109.12 \pm 0.56$ & $101.32 \pm 0.50$ & $106.12 \pm 0.16$ \\
\hline Disintegration time (min) & $1.99 \pm 0.02$ & $8.96 \pm 0.05$ & $10.95 \pm 0.08$ \\
\hline Hardness (N) & $117.63 \pm 0.15$ & $126.59 \pm 0.09$ & $131.42 \pm 0.04$ \\
\hline Friability (\%) & $0.75 \pm 0.02$ & $0.52 \pm 0.02$ & $0.43 \pm 0.03$ \\
\hline Tensile strength $\left(\mathrm{mN} / \mathrm{m}^{2}\right)$ & $2914.49 \pm 0.09$ & $3199.50 \pm 0.11$ & $3213.61 \pm 0.11$ \\
\hline HFR $^{*}$ & $158.52 \pm 0.04$ & $235.30 \pm 0.03$ & $320.79 \pm 0.09$ \\
\hline
\end{tabular}

\section{Total drug content}

Considering the total drug contents for TPH and HCTZ, statistical analysis showed significant differences in the total drug content across all the batches of TPH and HCTZ for MBPSP, lactose or DCP $(\mathrm{p}<0.05)$, but no batch was below $85 \%$ or above $115 \%$ of the average content. The British Pharmacopoeia ${ }^{9}$ specified that a product conforms to the test for total drug content if each individual content is in the range of $85 \%$ and 115 $\%$ of the average content.

\section{Tablet mechanical strength}

The force required to break the tablet is evaluated in kilogram or Newton. A tablet hardness of $4 \mathrm{~kg}(\approx 39 \mathrm{~N})$ is generally measured to be the least for satisfactory tablets ${ }^{10}$. Oral tablets normally have a hardness of $4-10$ $\mathrm{kg}(\approx 39-98 \mathrm{~N})$. Tablet hardness largely appreciates with regular storage of tablets and is influenced by the shape, chemical properties, binding agent and the compression pressure applied during compression ${ }^{\mathbf{1 1}, 12}$.

The friability test is closely correlated to tablet hardness and is designed to appraise the ability of the tablet to tolerate abrasion in packaging, handling and shipping. A friability of less than $1.00 \%$ is considered good especially for tablets produced by wet granulation but tablets produced by direct compression can give friability higher than unity ${ }^{\mathbf{1 3}}$.

Tensile strength is an added parameter employed to measure the mechanical properties of tablets. It is a measure of the bond strength of a tablet ${ }^{14}$.

The combination of the tablet hardness and friability, a term designated as the hardness-friability ratio (HFR) is another measure of mechanical strength of pharmaceutical tablets ${ }^{11,12,15}$. The hardness provides a measure of tablet strength while the friability is a measure of the tablet weakness. Studies have shown that the higher the HFR values, the stronger the tablet ${ }^{11,12}$.

However, the respective batches of tablets of TPH and HCTZ containing MBPSP, lactose or DCP maintained high values of mechanical strength with significant differences in the values of their tablet hardness, friability, tensile strength and hardness friability ratio (HFR) $(p<0.05)$. Tablets of TPH and HCTZ prepared with DCP generally showed higher values of mechanical strength than those of MBPSP and lactose. However, for the tablets of TPH, the order of mechanical strength was: DCP > MBPSP > lactose while in HCTZ, it was DCP > Lactose $>$ MBPSP.

\section{Disintegration time}

For most uncoated tablets, the British Pharmacopoeia specifies that the tablets disintegrates in 15 min (even though it varies for some uncoated tablets) while for coated tablets, up to 2 hours may be required ${ }^{9,16}$. Thus, the tablet disintegration test is restricted to production control of lot to lot disparities in the respective products and is not a degree of bioavailability ${ }^{17}$. Nevertheless, it is used to provide a simple and useful means for monitoring and controlling the quality of tablets. Ejiofor et al. ${ }^{18}$ stated that disintegration time has a direct relationship to tablet hardness.

Though the entire batches of TPH and HCTZ prepared with MBPSP, lactose or DCP disintegrated in less than $15 \mathrm{~min}$, there were significant differences across the respective batches of tablets of TPH and HCTZ prepared with MBPSP, lactose or DCP ( $p<0.05)$, with the tablets prepared with MBPSP disintegrating within the shortest time frame for both TPH and HCTZ. The order of disintegration time was as follows: MBPSP < lactose < DCP for TPH and HCTZ respectively. 


\section{Drug dissolution}

The dissolution profiles for TPH and HCTZ tablets are presented in Figures 1 and 2 respectively. The United States Pharmacopoeia (USP) ${ }^{19}$ specified that not less than $80.00 \%$ of the labelled amount of TPH should be dissolved in $45.00 \mathrm{~min}$. For the tablet of HCTZ, the USP also specified that not less than $60.00 \%$ of the labelled amount should be dissolved in $60.00 \mathrm{~min}$. From the dissolution rate profile of TPH tablet, at $45.00 \mathrm{~min}$, $73.13,87.72$ and $87.45 \%$ of TPH was released from the tablets prepared with lactose, MBPSP and DCP respectively (Figure 1) while for HCTZ tablets, at 60.00 min, 64.58, 57.84 and $66.00 \%$ of HCTZ was dissolved from the tablets prepared with lactose, MBPSP and DCP respectively (Figure 2 ). These results imply that the manufacture of TPH tablet using DCP and MBPSP as well as the preparation of HCTZ tablets using DCP and lactose complied with the USP requirements for drug release.

\section{CONCLUSION}

A new pharmaceutical excipient, MBPSP has been derived from the shell of the T. fuscata. It was applied as a diluent in the wet granulation method to produce TPH and HCTZ tablets in comparison with two commercial diluents, lactose and DCP. MBPSP compared very favourably with the commercial samples of lactose and DCP in the various tablet parameters used for evaluation. However, the tablets of TPH or HCTZ prepared with MBPSP displayed very significant shorter tablet disintegration time as well as maintaining a high value of mechanical strength. Therefore, the new

\section{REFERENCES}

1. Loyd V. Allen Jr, Popovich NG, Ansel HC. Ansel's Pharmaceutical Dosage Forms and Drug Delivery Systems. 8th Edition. Baltimore, Md: Lippincott Williams \& Wilkins. 2005, pp. 228-245.

2. Augsburger LL, Hoag SW (eds). Pharmaceutical Dosage Forms. In: Tablets (3rd edition), Volume 2: Rational Design and Formulation. New York, Informa Healthcare, 2008.

3. Gupta P, Nachaegari SK, Bansal AK. Improved excipient functionality by coprocessing. In: Katdare A, Chaubal MV CO Eds. Excipient Development for Pharmaceutical, Biotechnology and Drug Delivery systems. New York, Informa Healthcare, 2006. Pp. 109-126.

4. Moreton RC. Excipient functionality, Pharm Technol, 2004; 28: 98, 99,119.

5. Tousey MD. The manufacturing process: tablet and capsule manufacturing. Solid dose Experts Techceuticals Training. 2015; (15):1-12.

6. Ugoeze K.C, Chukwu A. Preliminary Evaluation of the Properties of Biomaterial of Tympanotonus fuscata shell as Pharmaceutical Excipient. Int. Res. J. Pharm. 2015; 6(2):104107.

7. Ugoeze K.C, Chukwu A. Physico-chemical Properties of a Modified Biomaterial from Tympanotonus Fuscata (Periwinkle) Shell Powder Considered as Pharmaceutical Excipient. Journal of Pharmaceutical and Allied Sciences, 2017; 14 (1):2417-2429.

8. Ugoeze K. C., Udeala O. K. Application of Periwinkle Shell Bio-ash (Ugoeze-bio-ash) as CO2 Donor in the Formulation of an Effervescent Low Dose Aspirin Tablet. American Journal of Biomedical Science and Engineering, 2015; 1(5):63-70.

9. British Pharmacopeia, 1998; Her Majesty’s Stationery Office, London. excipient, MBPSP could be a very useful excipient in the formulation of TPH and HCTZ immediate-release tablets.

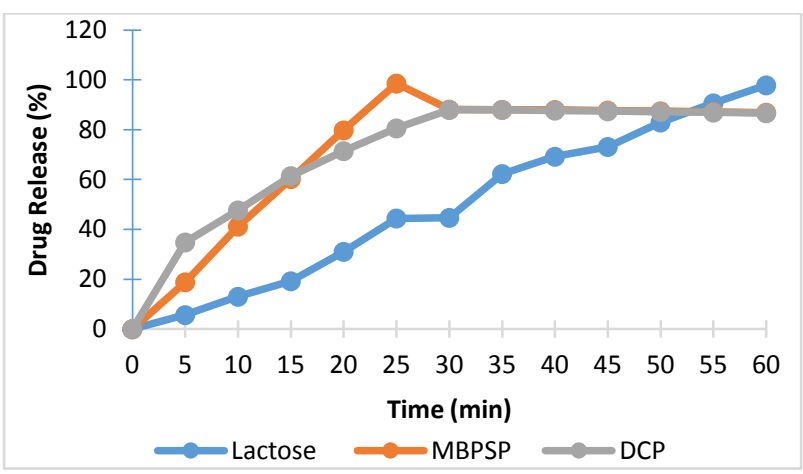

Figure 1: Dissolution rate profile for theophylline hydrate tablet prepared with lactose, MBPSP or dicalcium phosphate dihydrate (DCP) in $0.1 \mathrm{NHCl}$ at $37 \pm 1^{\circ} \mathrm{C}$

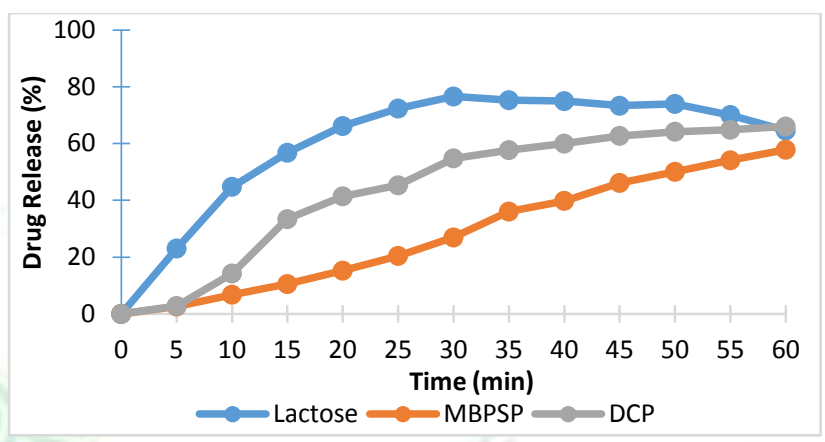

Figure 2: Dissolution profile for hydrochlorothiazide tablet prepared with lactose, MBPSP or dicalcium phosphate dihydrate in $0.1 \mathrm{NHCL}$ at $37 \pm 1^{\circ} \mathrm{C}$

10. Shangraw, R.F. Direct Compression Tabletting, Encyclopaedia of Pharmaceutical Technology, Vol.4, Marcel Dekker, U.S.A., 2nd ed., 1988; pp. 85-160.

11. Shangraw, R.F. Compressed tablets by direct compression granulation in: Pharmaceutical Dosage Forms: Tablets, Vol.1, Marcel Dekker, U.S.A., 2nd ed., 1989; p. 195-246.

12. Setn, B.B; Bandelin, F.J. and Shangraw, R.F. Tablets in: Pharmaceutical Dosage Forms, Vol. I; Liebermann, H. and Lachman, L. (eds.), Marcel Dekker Inc, New York, 1980; p. 110 .

13. Marks, A.M. \& Sciarra, J.J. Effects of size and other physical properties of granules and their corresponding tablets, J. Pharm. Sci. 1968; 57:497.

14. Parrot, E.L. Pharmaceutical Technology; Fundamental Pharmaceutics, Burges Pub. Co., Minneapolis, 1970; pp. 17$18,74$.

15. Lazarus, J. and Lachman, L. Experiences in development of directly compressible tablets containing potassium chloride, J. Pharm. Sci. 1966; 55: 1121.

16. Rasenack, N. and Muller, B.W. Crystal habit and tableting behaviour, Int. J. Pharm. 2002; 244:45-57.

17. Sherringtonn, P.J.; Oliver, R. Granulation: in: Encyclopaedia of Pharmaceutical Technology, Vol. 3, 2nd Edition, Edited by James Swarbrick and James C. Boylan, Marcel Dekker, Inc. New York, 1981; pp. 2713-2731.

18. Ejiofor, O; Esezobo, S, Pilpel, N. The plasto-elasticity and compressibility of coated powders and the tensile strength of their tablets, J. Pharm. Pharmac. 1986; 38 (1):1-7.

19. The United States Pharmacopoeia, U.S.P, NF. The United States Pharmacopoeial Convention, Rockville, 2007. 